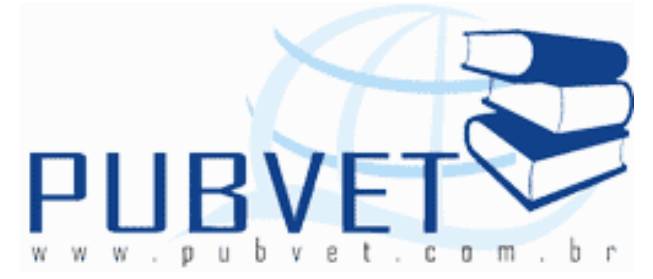

PUBVET, Publicações em Medicina Veterinária e Zootecnia.

\title{
Resposta de Brachiaria brizantha cv. Marandu a regimes de desfolhação em Porto Velho, Rondônia
}

\section{Newton de Lucena Costa ${ }^{1}$, Carlos Alberto Gonçalves ${ }^{2}$, José Ribamar da Cruz Oliveira ${ }^{3}$, Maria Alice Santos Oliveira ${ }^{4}$, João Avelar Magalhães ${ }^{5}$, Raimundo Bezerra de Araújo Neto ${ }^{6}$}

${ }^{1}$ Eng. Agr., D.Sc., Embrapa Roraima. Boa Vista, Roraima.

${ }^{2}$ Eng. Agr., M.Sc., Embrapa Amazônia Oriental. Belém, Pará.

${ }^{3}$ Eng. Agr., M.Sc., Embrapa Rondônia. Porto Velho, Rondônia.

${ }^{4}$ Eng. Agr., M.Sc., Embrapa Cerrados. Brasília, Distrito Federal.

${ }^{5}$ Méd.Vet., D.Sc., Embrapa Meio-Norte. Parnaíba, Piauí.

${ }^{6}$ Eng. Agr., M.Sc., Embrapa Meio-Norte. Teresina, Piauí.

\section{Resumo}

Objetivou-se determinar a frequência e a intensidade de desfolhação mais adequada para o manejo de pastagens de Brachiaria brizantha cv. Marandu, nas condições ecológicas de Porto Velho, Rondônia. O delineamento experimental foi em blocos casualizados com parcelas divididas e três repetições. As frequências de desfolhação $(21,28,35$ e 42 dias) representavam as parcelas principais e as intensidades de desfolhação (20 e $40 \mathrm{~cm}$ ), as subparcelas. As maiores produções de forragem foram observadas quando a $B$. brizantha cv. Marandu era cortada a cada 35 e 42. Os cortes realizados a cada 21 dias, independentemente da intensidade de desfolhação, 
proporcionaram maiores teores de proteína bruta (PB), contudo os maiores rendimentos de PB foram obtidos com cortes a cada 28, 35 ou 42 dias e a 40 $\mathrm{cm}$ acima do solo. Os maiores teores de fósforo, cálcio e potássio, independentemente da intensidade de desfolhação, foram registrados com cortes a cada 21 dias. Visando conciliar produção e qualidade da forragem, os resultados indicam que o melhor manejo de $B$. brizantha $\mathrm{cv}$. Marandu consiste em frequências de desfolhação de 42 dias, independentemente de sua intensidade, ou frequências de 35 dias e a $40 \mathrm{~cm}$ acima do solo.

Termos para indexação: cálcio, fósforo, matéria seca, potássio, proteína bruta

\section{Response of Brachiaria brizantha cv. Marandu to defoliation regimes in Porto Velho, Rondônia}

\section{Abstract}

Objective was to determine the frequency and intensity of defoliation more appropriate for management pasture of Brachiaria Brizantha in ecological conditions of Porto Velho, Rondônia. The experimental design was randomized blocks with split plots and three replications. The defoliation frequencies (21, 28,35 and 42 days) represented the main plots and defoliation intensity (20 and $40 \mathrm{~cm}$ ) the subplots. The highest forage yield were observed when the grass was cut every 35 and 42 days. The defoliation frequency every 21 days, regardless of defoliation intensity, provided higher crude protein (CP), however the highest CP yields were obtained with defoliations every 28,35 or 42 days and $40 \mathrm{~cm}$ above the ground. The highest concentrations of phosphorus, calcium and potassium, irrespective of the defoliation intensity, were recorded with frequency defoliation every 21 days. Aiming to combine the production and quality of forage, the results indicate that better management of $B$. brizantha cv. Marandu consists of defoliation frequency every 42 days, regardless of defoliation intensity, or cutting at 35 days and $40 \mathrm{~cm}$ above the ground.

Index terms: calcium, crude protein, dry matter, phosphorus, potassium 
COSTA, N.L. et al. Resposta de Brachiaria brizantha cv. Marandu a regimes de desfolhação em Porto Velho, Rondônia. PUBVET, Londrina, V. 8, N. 6, Ed. 255, Art. 1688, Março, 2014.

\section{Introdução}

As pastagens representam a fração mais econômica que compõe a alimentação dos bovinos e, como tal, constituem a base de sustentação da atividade pecuária nos trópicos. A área de pastagem no Brasil está estimada em 260 milhões de hectares, sendo que aproximadamente 115 milhões de hectares são pastagens com espécies cultivadas, e em 145 milhões predominam as gramíneas nativas. Estes pastos alimentam aproximadamente 235 milhões de animais (Ciero, 2005).

Nas últimas décadas foram introduzidas no país várias espécies de gramíneas visando aumentar a produção e a qualidade de forragem, dentre elas se destacou a Brachiaria brizantha cv. Marandu (Pereira, 2002). No Brasil Central, região onde a pecuária se tornou um dos principais segmentos do agronegócio nacional, $45 \%$ das pastagens são formadas pelo capim-Marandu (Soares Filho, 2008). Atualmente é a gramínea forrageira tropical com maior volume de sementes comercializadas anualmente em todo o país (Macedo, 2005).

O capim-Marandu é originário do continente africano, encontra-se amplamente distribuído na maioria dos cerrados tropicais e em áreas anteriormente sob vegetação de florestas da região amazônica. Vegeta bem em altitudes que variam desde o nível do mar até $1.800 \mathrm{~m}$, principalmente em regiões com precipitações entre 1.000 e 3.500 mm/ano. Apresenta boa adaptação e produção de forragem em solos de média fertilidade natural; excelente comportamento em solos arenosos; sistema radicular profundo o que permite a obtenção de água durante os períodos de seca; requer solos bem drenados e não tolera o encharcamento prolongado; boa resistência ao ataque das cigarrinhas-das-pastagens (Deois incompleta, D. flavopicta, Notozulia entreriana); apresenta maior palatabilidade que as outras espécies de Brachiaria (Costa et al., 2004).

No manejo de pastagens, diversos fatores relacionados com a resposta morfofisiológica e a sobrevivência das plantas forrageiras devem ser considerados, destacando-se o estádio de crescimento e a intensidade de 
desfolhação, que afetam marcadamente o rendimento e a qualidade da forragem produzida. Em geral, o aumento da frequência de desfolhação resulta em incrementos significativos da produção de forragem, contudo, paralelamente, ocorre decréscimo em seu valor nutritivo. Já, a intensidade de desfolhação é importante no rebrote pela eliminação ou não de meristemas apicais, área foliar remanescente e pela diminuição ou não das reservas orgânicas acumuladas (Corsi, 1972).

Este trabalho teve por objetivo determinar a frequência e a intensidade de desfolhação mais adequada para o manejo de pastagens de Brachiaria brizantha cv. Marandu, nas condições ecológicas de Porto Velho, Rondônia.

\section{Material e Métodos}

O ensaio foi conduzido no Campo Experimental da Embrapa Rondônia, localizado em Porto Velho. O clima da região é tropical úmido do tipo Am, com precipitação anual entre 2.000 a $2.500 \mathrm{~mm}$; temperatura média anual de $24,9^{\circ} \mathrm{C}$ e umidade relativa do ar de $83 \%$. O solo da área experimental é um Latossolo Amarelo, textura argilosa, fase floresta, com as seguintes características químicas: $\mathrm{pH}=5,2 ; \mathrm{Al}=1,8 \mathrm{cmol} / \mathrm{dm}^{3} ; \mathrm{Ca}+\mathrm{Mg}=1,3$ $\mathrm{cmol} / \mathrm{dm}^{3} ; \mathrm{P}=2 \mathrm{mg} / \mathrm{kg}$ e $\mathrm{K}=55 \mathrm{mg} / \mathrm{kg}$.

O delineamento experimental foi em blocos casualizados com parcelas divididas e três repetições. As frequências de desfolhação $(21,28,35$ e 42 dias) representavam as parcelas principais e as intensidades de desfolhação (20 e $40 \mathrm{~cm}$ ), as subparcelas. O plantio foi realizado em linhas espaçadas de 0,5 $\mathrm{m}$, utilizando-se $6 \mathrm{~kg}$ de sementes/ha (Valor Cultural $=60 \%$ ). Cada parcela foi constituída por quatro linhas de 4,0 m de comprimento, utilizandose as duas linhas centrais como área útil e como bordadura uma linha em cada lateral e 0,5 m nas extremidades. Durante o período experimental foram realizados 22, 16, 12 e 10 cortes, respectivamente para as frequências de desfolhação de 21, 28, 35 e 42 dias. Os parâmetros avaliados foram rendimento de matéria seca (MS), teores e produções de proteína bruta (PB) e teores de fósforo, cálcio e potássio. 
COSTA, N.L. et al. Resposta de Brachiaria brizantha cv. Marandu a regimes de desfolhação em Porto Velho, Rondônia. PUBVET, Londrina, V. 8, N. 6, Ed. 255, Art. 1688, Março, 2014.

\section{Resultados e Discussão}

A análise da variância revelou efeito significativo $(P<0,05)$, tanto da frequência quanto da intensidade de desfolhação sobre os rendimentos de MS da gramínea (Tabela 1). Cortes a cada 35 e 42 dias proporcionaram maiores produções de forragem, sendo isto consequência do maior período de tempo que a planta dispõe para o acúmulo de MS. Já, cortes a cada 28 dias implicaram nas menores produções, pois a constante remoção da folhagem, além de não permitir acúmulo satisfatório de reservas orgânicas, propicia rebrotas menos vigorosas. Da mesma forma, Costa \& Oliveira (1994) obtiveram incrementos de 182 e 101\%, na produção de MS do capimguenoaro (Paspalum guenorarum Arech.), respectivamente para os períodos seco e chuvoso, efetuando cortes a cada 63 dias, em comparação com cortes a cada 42 dias. Influências da frequência de desfolhação sobre o rendimento de forragem de gramíneas forrageiras também foram encontradas por Rodrigues et al. (2005) e Magalhães et al. (2006), em pastagens de Panicum maximum cv. Tanzânia e Pennisetum purpureum cv. Napier, respectivamente.

Tabela 1. Rendimento de matéria seca de Brachiaria brizantha cv. Marandu, em função da frequência e intensidade de desfolhação em Porto Velho, Rondônia.

\begin{tabular}{ccc}
\hline $\begin{array}{c}\text { Frequência de desfolhação } \\
\text { (dias) }\end{array}$ & $\begin{array}{c}\text { Intensidade de } \\
\text { desfolhação }(\mathrm{cm})\end{array}$ & $\begin{array}{c}\text { Rendimento de Matéria seca } \\
(\mathrm{t} / \mathrm{ha})\end{array}$ \\
\hline 21 & 20 & $16,2 \mathrm{f}$ \\
28 & 40 & $19,0 \mathrm{e}$ \\
$21,9 \mathrm{~d}$ & $26,3 \mathrm{~b}$ \\
35 & 20 & $23,4 \mathrm{C}$ \\
& 20 & $29,1 \mathrm{a}$ \\
42 & 40 & $30,7 \mathrm{a}$ \\
\hline
\end{tabular}

- Na coluna, médias seguidas da mesma letra não difere entre si pelo teste Tukey $(P>0,05)$

Com relação à intensidade de desfolhação, as maiores produções de MS foram obtidas com cortes a $40 \mathrm{~cm}$ acima do solo, para cortes a cada 21, 28 ou 35 dias, enquanto que na frequência de desfolhação de 42 dias, não se observou efeito significativo $(P>0,05)$ da intensidade de desfolhação (Tabela 1). Costa \& Saibro (1990), verificaram que cortes a $10 \mathrm{~cm}$ acima do solo, 
independentemente do estádio de crescimento das plantas (vegetativo ou florescimento), resultaram em maiores rendimentos de MS do capim-guenoaro cv. Baio, além de fornecerem uma melhor distribuição estacional da forragem durante o ano. Segundo Corsi (1972) e Costa \& Saibro (1985), as plantas forrageiras manejadas sob resíduos mais altos, por reterem maiores quantidades de tecido foliar fotossinteticamente ativos e ocorrer menor remoção de meristemas apicais, tornam-se mais produtivas, com o decorrer do tempo, que aquelas submetidas a cortes mais intensos, o que assegura maior persistência da pastagem.

Os maiores teores de PB, independentemente da intensidade de desfolhação, foram registrados com cortes a cada 21 dias (Tabela 2). Este fato tem sido bastante relatado na literatura, como mostra os trabalhos de Prates (1977), Costa \& Saibro (1984) e Vilarreal (1994). Para as demais frequências de desfolhação não se observou efeito significativo $(P>0,05)$ da intensidade de desfolhação. Considerando-se que teores de PB inferiores a 7\% são limitantes à produção animal (Minson, 1984), por implicarem em menor consumo voluntário, redução na digestibilidade e balanço nitrogenado negativo, observa-se que a gramínea, excetuando-se corte aos 42 dias de rebrota, atenderia aos requerimentos proteicos mínimos dos ruminantes.

Com relação aos rendimentos de $\mathrm{PB}$, os maiores valores foram registrados com cortes a cada 28, 35 ou 42 dias e a $40 \mathrm{~cm}$ acima do solo (Tabela 2). Estes resultados demonstram um efeito compensatório entre produção de forragem e teores de PB, conforme verificado por Lima \& Gondim (1982) e Costa \& Oliveira (1994) avaliando diversas espécies do gênero Paspalum. No entanto, Prates (1977) verificou que plantas de P. notatum, cortadas em estádios mais jovens de crescimento, apresentaram maiores rendimentos de $\mathrm{PB}$, como decorrência de uma acentuada diminuição do teor protéico com o envelhecimento das plantas. 
COSTA, N.L. et al. Resposta de Brachiaria brizantha cv. Marandu a regimes de desfolhação em Porto Velho, Rondônia. PUBVET, Londrina, V. 8, N. 6, Ed. 255, Art. 1688, Março, 2014.

Tabela 2. Teores e rendimento de proteína bruta (PB) de Brachiaria brizantha cv. Marandu, em função da frequência e intensidade de desfolhação em Porto Velho, Rondônia.

\begin{tabular}{cccc}
\hline $\begin{array}{c}\text { Frequência de } \\
\text { desfolhação (dias) }\end{array}$ & $\begin{array}{c}\text { Intensidade de } \\
\text { desfolhação }(\mathrm{cm})\end{array}$ & $\begin{array}{c}\text { Teores de PB } \\
(\%)\end{array}$ & $\begin{array}{c}\text { Rendimento de PB } \\
(\mathrm{kg} / \mathrm{ha})\end{array}$ \\
\hline 21 & 20 & $9,98 \mathrm{a}$ & $1.454 \mathrm{~d}$ \\
& 40 & $9,11 \mathrm{a}$ & $1.730 \mathrm{~cd}$ \\
28 & 20 & $7,98 \mathrm{~cd}$ & $1.747 \mathrm{c}$ \\
& 40 & $8,38 \mathrm{bc}$ & $2.203 \mathrm{a}$ \\
35 & 20 & $7,44 \mathrm{~d}$ & $1.741 \mathrm{c}$ \\
& 40 & $7,95 \mathrm{~cd}$ & $2.313 \mathrm{a}$ \\
42 & 20 & $6,24 \mathrm{e}$ & $1.916 \mathrm{bc}$ \\
& 40 & $6,55 \mathrm{e}$ & $2.063 \mathrm{a}$ \\
\hline
\end{tabular}

- Nas colunas, médias seguidas da mesma letra não difere entre si pelo teste Tukey $(P>0,05)$

Com relação aos teores de fósforo, cálcio e potássio, os maiores valores foram obtidos com cortes a cada 21 dias, sendo observado efeito significativo $(P>0,05)$ da intensidade de desfolhação apenas para o fósforo com cortes a cada 28 dias, onde a intensidade de desfolhação de $40 \mathrm{~cm}$ apresentou maior concentração do nutriente (Tabela 3 ). Tal fato pode ser consequência do efeito natural de diluição dos nutrientes, em função dos maiores acúmulos de MS e da maior proporção de tecidos estruturais da gramínea com a redução da frequência de desfolhação. Resultados semelhantes foram reportados por Prates (1977) para genótipos de $P$. notatum, e por Costa et al. (2003) para $B$. brizantha cv. Xaraés, submetidos a diferentes intervalos de desfolhação.

Tabela 3. Teores $(\mathrm{g} / \mathrm{kg})$ de fósforo $(\mathrm{P})$, potássio $(\mathrm{K})$ e cálcio $(\mathrm{Ca})$ de Brachiaria brizantha cv. Marandu, em função da frequência e intensidade de desfolhação em Porto Velho, Rondônia.

\begin{tabular}{ccccc}
\hline $\begin{array}{c}\text { Frequência de } \\
\text { desfolhação (dias) }\end{array}$ & $\begin{array}{c}\text { Intensidade de } \\
\text { desfolhação }(\mathrm{cm})\end{array}$ & $\mathrm{P}$ & $\mathrm{K}$ & $\mathrm{Ca}$ \\
\hline 21 & 20 & $1,78 \mathrm{a}$ & $17,58 \mathrm{a}$ & $4,81 \mathrm{a}$ \\
& 40 & $1,82 \mathrm{a}$ & $17,25 \mathrm{ab}$ & $4,77 \mathrm{a}$ \\
28 & 20 & $1,53 \mathrm{c}$ & $16,70 \mathrm{c}$ & $3,87 \mathrm{~b}$ \\
& 40 & $1,62 \mathrm{~b}$ & $16,91 \mathrm{bc}$ & $3,59 \mathrm{bcd}$ \\
35 & 20 & $1,49 \mathrm{~cd}$ & $15,73 \mathrm{~d}$ & $3,39 \mathrm{bcd}$ \\
& 40 & $1,42 \mathrm{~d}$ & $16,11 \mathrm{~d}$ & $3,45 \mathrm{bcd}$ \\
42 & 20 & $1,39 \mathrm{~d}$ & $15,62 \mathrm{~d}$ & $3,36 \mathrm{~cd}$ \\
& 40 & $1,41 \mathrm{~d}$ & $15,89 \mathrm{~d}$ & $3,11 \mathrm{~d}$ \\
\hline
\end{tabular}

- Nas colunas, médias seguidas da mesma letra não difere entre si pelo teste Tukey $(P>0,05)$ 
COSTA, N.L. et al. Resposta de Brachiaria brizantha cv. Marandu a regimes de desfolhação em Porto Velho, Rondônia. PUBVET, Londrina, V. 8, N. 6, Ed. 255, Art. 1688, Março, 2014.

\section{Conclusões}

- Frequências de desfolhação de 21 dias, independentemente de sua intensidade, proporcionam maiores teores de $\mathrm{PB}$, contudo os maiores rendimentos de PB são obtidos com cortes a cada 28, 35 ou 42 dias e a $40 \mathrm{~cm}$ acima do solo.

- Os maiores teores de fósforo, cálcio e potássio, independentemente da intensidade de desfolhação, são registrados com cortes a cada 21 dias.

- Visando conciliar produção e qualidade da forragem, os resultados indicam que o melhor manejo de $B$. brizantha $\mathrm{cv}$. Marandu consiste em frequências de desfolhação de 42 dias, independentemente de sua intensidade, ou frequências de 35 dias e a $40 \mathrm{~cm}$ acima do solo.

\section{Referências Bibliográficas}

CIERO, L.D. A sustentabilidade das pastagens brasileiras e o plantio direto. Revista Plantio Direto, v.88, n.4, 2005.

CORSI, M. Estudos da produtividade e do valor nutritivo do capim-elefante (Pennisetum purpureum Schum.), variedade Napier submetido a diferentes frequências e alturas de corte. Piracicaba: ESALQ,1972. 139 p. Tese de Doutorado.

COSTA, N. de L.; OLIVEIRA, J.R. da C. Avaliação de gramíneas forrageiras do gênero Paspalum em Rondônia. Lavoura Arrozeira, v. 47, n. 412, p. 18-20, 1994.

COSTA, N. de L.; GONÇALVES, C.A.; OLIVEIRA, M.A.S.; TOWNSEND, C.R.; MAGALHÃES, J.A. Germoplasma forrageiro para a formação de pastagens. In: COSTA, N. de L. (Org.). Formação, manejo e recuperação de pastagens em Rondônia. Porto Velho: Embrapa Rondônia, 2004, p. 31-83.

COSTA, N de L.; TOWNSEND, C.R.; MAGALHÃES, J.A. Avaliação agronômica de Brachiaria brizantha cv. Xaraés em diferentes idades de corte. In: REUNIÃO ANUAL DA SOCIEDADE BRASILEIRA DE ZOOTECNIA, 40., 2003, Santa Maria. Anais... Santa Maria: SBZ, 2003. 5 p. (CD-ROM).

COSTA, N. de L.; SAIBRO, J.C. de. Adubação nitrogenada, épocas e alturas de corte em Paspalum guenoarum Arech. Agronomia Sulriograndense, v.20, n.1, p.33-49, 1984.

COSTA, N. de L.; SAIBRO, J.C. de. Estabelecimento e regimes de corte de alfafa e Paspalum guenoarum sob cultivo estreme e consorciado. Pesquisa Agropecuária Brasileira, v.20, n.12, p.1433-1442, 1985.

COSTA, N. de L.; SAIBRO, J.C. de. Regimes de corte e rendimento estacional de forragem de Paspalum guenoarum Arech. Pesquisa Agropecuária Brasileira, v.25, n.9, p.1349-1355, 1990.

LIMA, R.R.; GONDIM, A.G. Avaliação de forrageiras nativas especialmente do gênero Paspalum. Belém: FCAP, 1982. 41p. (FCAP. Informe Técnico, 9). 
MACEDO, M.C.M. Pastagens no ecossistema Cerrados: evolução das pesquisas para o desenvolvimento sustentável. In: REUNIÃO ANUAL DA SOCIEDADE BRASILEIRA DE ZOOTECNIA, 42., 2005, Goiânia. A produção animal e o foco no agronegócio. Anais... Goiânia: Sociedade Brasileira de Zootecnia: Universidade Federal de Goiás, 2005. p.56-84.

MAGALHÃES, J.A.; LOPES, E.A.; RODRIGUES, B.H.N.; COSTA, N. de L.; BARROS, N.N.; MATTEI, D.A. Influência da adubação nitrogenada e da idade de corte sobre o rendimento forrageiro do capim-elefante. Revista Ciência Agronômica, v.37, p.91/16-96, 2006.

MINSON, D.J. Effects of chemical and physical composition of herbaje eaten upon intake. In: HACKER, J.B. (Ed.) Nutritional limits to animal production from pasture. Farnham Royal: CAB. p.167-182, 1984.

PEREIRA, A.V. Avanços no melhoramento genético de gramíneas forrageiras tropicais. In: REUNIÃO ANUAL DA SOCIEDADE BRASILEIRA DE ZOOTECNIA, 39, 2002. Recife. Anais... Recife: SBZ, 2002. p.19-41.

PRATES, E.R. Efeito de doses de nitrogênio e de intervalos entre cortes sobre a produção e composição de dois ecótipos de Paspalum notatum Flügge. e da cultivar pensacola de Paspalum notatum Flüegge. var. Saurae Parodi. Anuário Técnico do Instituto de Pesquisas Zootécnicas Francisco Osório, v.4, n.1, p.267-307, 1977.

RODRIGUES, B.H.N.; MAGALHÃES, J.A.; CAVALCANTE, R.F.; BARROS, W.S. Efeito da idade de corte sobre o rendimento forrageiro do capim-tanzânia irrigado nos Tabuleiros Litorâneos do Piauí. Revista Científica de Produção Animal, v.8, p.21-27, 2006.

SOARES FILHO, C.V. Compensa produzir sementes de braquiárias. http.://www.foa.unesp.br/pesquisa/centros_e_nucleos/zootecnia/informacoes_tecnicas/forragi cultura/Compensa\%20produzir\%20sementes\%20de\%20Braqui\%C3\%A1ria.pdf.

VILARREAL, M. Valor nutritivo de gramíneas y leguminosas forrajeras en San Carlos, Costa Rica. Pasturas Tropicales, v.16, n.1, p.27-31, 1994. 